\title{
Patrimonio como valor. Nuevas herramientas para la participación de las comunidades en la puesta en valor del patrimonio cultural
}

Guido Cimadomo | Dpto. Arte y Arquitectura, Universidad de Málaga

URL de la contribución <www.iaph.es/revistaph/index.php/revistaph/article/view/3804>

La Convención sobre el Valor Patrimonial Cultural para la Sociedad, firmada en Faro en 2005 por el Consejo de Europa puede considerarse un hito para el rol de las comunidades en la conservación y protección del patrimonio cultural. Su carácter singular reside en enfatizar el valor y potencial del patrimonio cultural para ser utilizado como un recurso para el desarrollo sostenible y para fomentar la calidad de vida en una sociedad en permanente evolución, así como para consolidar la cohesión social a través de la promoción de una responsabilidad compartida sobre los lugares habitados. El concepto de comunidad patrimonial ha sido definido, posiblemente por primera vez en esta Convención, como un grupo que valora aspectos específicos del patrimonio cultural que quiere proteger y transmitir a las generaciones futuras, además de reflejar la necesidad de una participación pública en las decisiones relacionadas con el patrimonio cultural.

La tendencia que se puede vislumbrar impulsa un entendimiento del patrimonio como valor que requiere de la participación activa de todos los actores posibles en las diferentes fases, desde la identificación a la regeneración y gestión. Así su protección no recae solamente en las administraciones, sino que pretende incluir a las comunidades locales, reforzando el cambio desde el "patrimonio por asignación" hacia un "patrimonio por apropiación", en el cual son los ciudadanos los que solicitan la inclusión de otro tipo de elementos patrimoniales, bajo criterios más subjetivos que los habituales (RAUTENBERG, 1998; TWEED, 2007; CIMADOMO, 2015). Experiencias recientes como la rehabilitación de Virxe da Barca in Muxía (JIMÉNEZ-ESQUINAS; SÁNCHEZ-CARRETERO, 2015) o el proceso en acto en Sevilla para la recuperación y puesta en valor de las Atarazanas, muestran como en la actualidad las comunidades locales no están consideradas como actores a tener en cuenta durante las fases decisionales, generando conflictos, reclamaciones y retrasos.

Aunque la mediación es un procedimiento que puede resolver parte de estos conflictos, y que cada vez es más valorada, otras experiencias en el resto de Europa muestran que vincular las comunidades desde etapas tempranas, fomentando su participación e incluso la toma de decisiones, puede dar resultados de interés en el esfuerzo para la preservación del patrimonio cultural. Comparados con la rigidez de los tradicionales y habituales procesos de rehabilitación y protección impulsados desde arriba en nuestro país, nuevas soluciones creativas son posibles, activando la participación ciudadana, que se vuelve una parte activa de la solución (CIMADOMO, 2013). El patrimonio es más que la suma de objetos reconocidos merecedores de ser protegidos, y debe ser considerado como un sistema territorial en el cual las relaciones entre bienes físicos y actividades humanas sean un todo integral (PARENTE, 2012).

Entre los ejemplos de éxito que merece la pena reseñar se encuentra el Scotland's Coastal Heritage at Risk Project, dirigido a la protección del patrimonio arqueológico de la costa de Escocia de más de 15.000 km, en riesgo por el cambio climático que origina la erosión y la subida del nivel del mar. El Shorewatch Project, promovido por la Scottish Coastal Archaeologicy and Problem of Erosion organization (SCAPE) desde 2001, y financiado por la Heritage Lottery Fund, busca la colaboración de voluntarios y de colectivos para la monitorización de la costa y de los más de 12.000 sitios arqueológicos existentes, algunos desconocidos por la misma administración. La utilización de formularios básicos, de fotografías y de croquis, unidas a las potencialidades de las tecnologías de la información, han permitido a los servicios patrimoniales documentar, actualizar y en oca- 


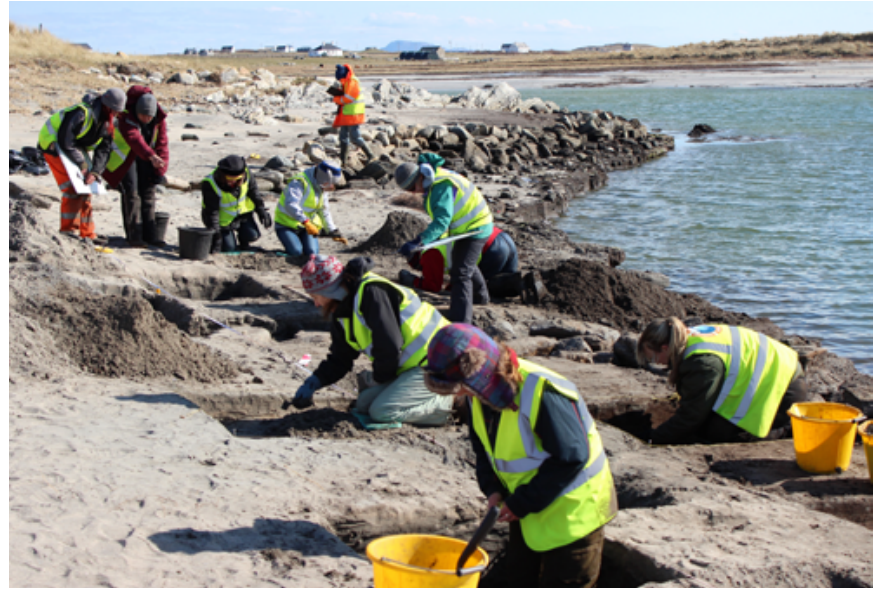

Excavaciones arqueológicas por voluntarios en Loch Paible (Escocia) | foto Tom Dawson/SCAPE

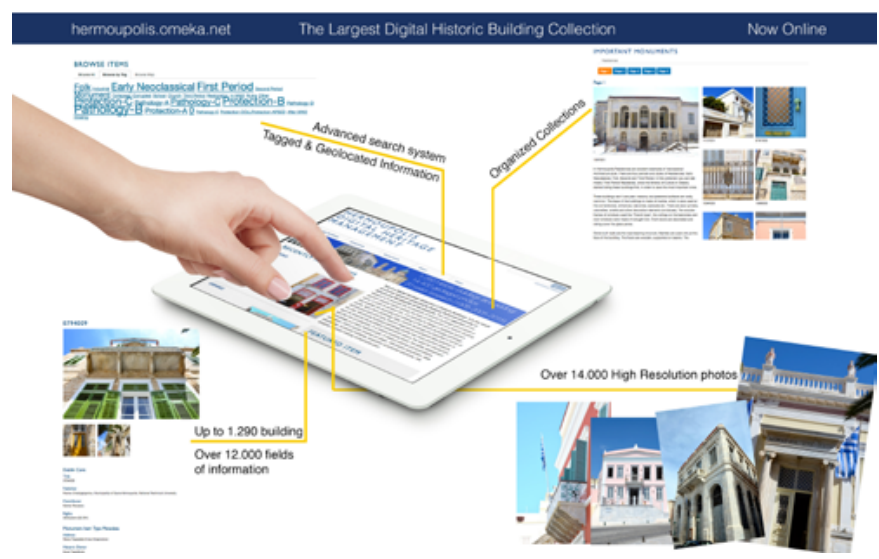

Participación ciudadana a través de la aplicación web del proyecto HERMES | infografía P. Chatzigrigoriou

siones identificar a los sitios arqueológicos presentes a lo largo de la costa (DAWSON et ál., 2013). La utilización de aplicaciones para móviles y de páginas web a través de las cuales realizar todas las tareas de documentación ha permitido simplificar estos procesos, además de permitir la participación de un amplio sector de la población. Las últimas estadísticas publicadas muestran la realización de 849 encuestas, con más de 1600 imágenes subidas al portal de la administración. Como continuación de esta experiencia se ha realizado una convocatoria en la cual las comunidades locales pueden proponer un proyecto a desarrollar en uno de los

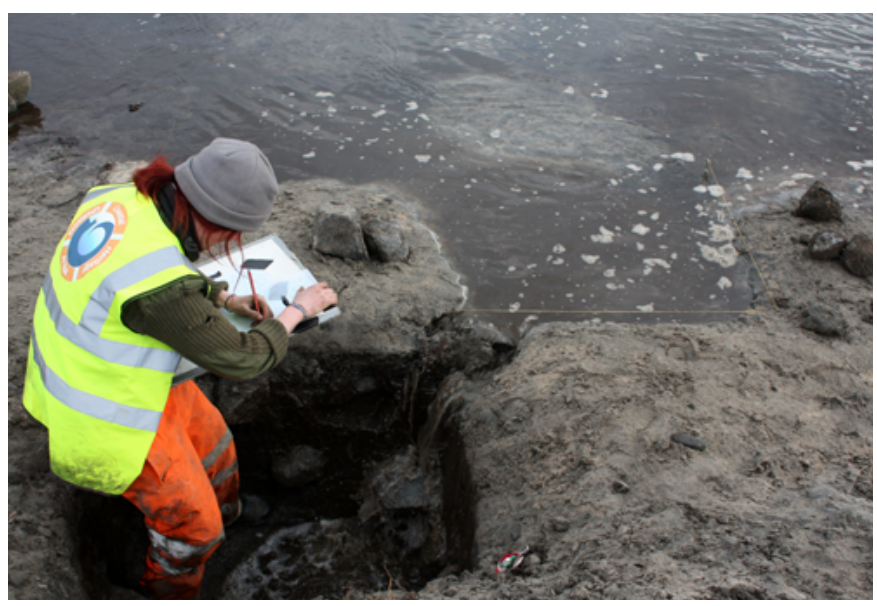

Actividades de documentación por parte de voluntarios en Loch Paible, Escocia | foto Tom Dawson/SCAPE

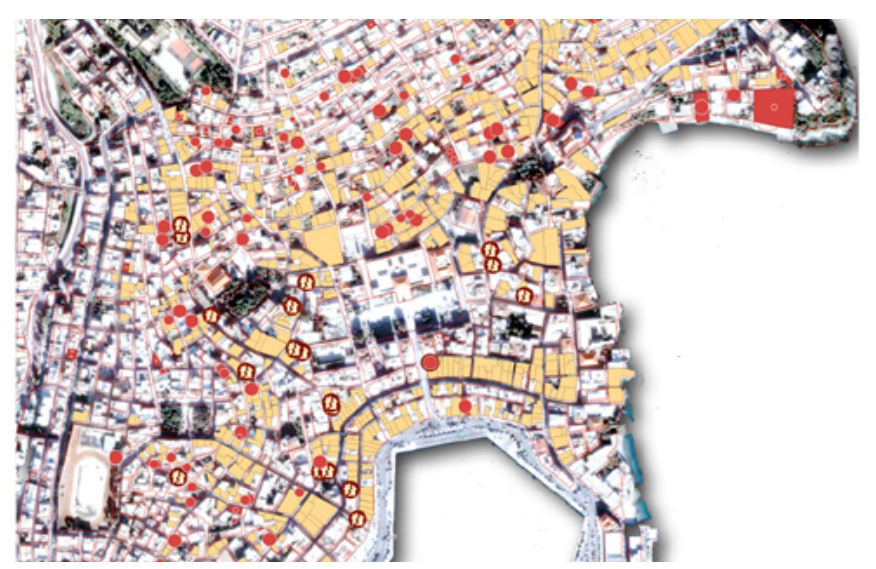

Factores de riesgo en edificios de la ciudad de Hermópolis. A mayor tamaño de los círculos, mayor necesidad social de intervención | infografía P. Chatzigrigoriou

lugares prioritarios seleccionados por SCAPE. Los resultados de ShoreDIG, que ha ofrecido una amplia libertad en cuanto a las acciones propuestas, ha permitido, entre otros, la documentación digital de las pinturas de las Wemyss Caves, cuyo resultado es una reproducción 3D digital, o la campaña de vuelos para documentar fotográficamente algunas zonas inaccesibles próximas a Edimburgo, realizada por la UK Civil Air Patrol Lowland and Highland Units. Al final de este proyecto, no sólo se habrá conseguido identificar lugares de interés y lugares en riesgo, mejorando la gestión del patrimonio costero escocés, sino también vincular a las comunidades 
a debate Relaciones entre ciudadanía y agentes patrimoniales. Colaboración, conflicto y mediación

| coordinan Cristina Sánchez-Carretero, Guadalupe Jiménez-Esquinas

con su propio patrimonio, haciendo ver la necesidad de colaboración, pero también demostrando que las ideas y planteamientos de la población sobre como intervenir en estos lugares no solamente es viable, sino que a veces resultan en proyectos que la misma administración no se había planteado, poniendo en carga las capacidades y experiencias de las propias comunidades.

Un segundo ejemplo que busca la participación de la población desde las primeras fases de desarrollo es el Heritage Management E-System (HERMES) en la isla griega de Hermopolis, donde la situación económica general de los últimos años ha perjudicado la posibilidad de intervención sobre el patrimonio edificado en abandono y deterioro. El uso de GIS y de bases de datos relacionales, junto con una clasificación de aproximadamente 200 especificaciones subdivididas en 10 categorías, ha permitido la catalogación de aproximadamente 1000 edificios, ofreciendo un conocimiento detallado de las patologías y problemas del casco histórico, paso previo para la protección de su carácter ambiental, alejándose de la idea de protección de unos edificios aislados. De este modo ha sido posible priorizar las intervenciones en función de los recursos disponibles, gracias también a criterios más detallados definidos a través de cuestionarios en línea, jerarquizando el impacto social, el peso del edificio en la ciudad, la sensibilidad de usos de edificios próximo (CHATZIGRIGORIOU; MAVRIKAS, 2013). Además de poder intervenir sobre el patrimonio de la ciudad de una manera más coherente, el proyecto ha permitido ofrecer información más detallada a los ciudadanos, haciéndoles partícipes de los valores del casco histórico a la vez que le permite complementar esta información con la información oral y fotográfica particular.

Estos ejemplos demuestran que una actitud más abierta y dialogante de las administraciones, buscando la participación temprana de las comunidades locales, incluso para plantear intervenciones no previamente planificadas, no solamente produce beneficios para el patrimonio, sino que incide favorablemente sobre los recursos necesarios, sobre los resultados, y en definitiva sobre la apropiación del patrimonio, que pasa de ser una carga y responsabilidad alejada a ser un valor exigido y reclamado por las propias comunidades locales, generando su participación activa en todas las fases del proceso.

\section{BIBLIOGRAFÍA}

- CHATZIGRIGORIOU, P.; MAVRIKAS, E. (2013) Saving Historic buildings with multi-criteria GIS tool. The case of Hermoupolis - Cyclades. En 2013 Digital Heritage International Congress (DigitalHeritage). sl: IEEE, 2013, vol. 2, pp. 53-59

- CIMADOMO, G. (2013) Documentation and dissemination of Digital Heritage. Current solutions and considerations about its digital implementation. En En 2013 Digital Heritage International Congress (DigitalHeritage). sl: IEEE, 2013, vol. 1, pp. 555-562

- CIMADOMO, G. (2015) Community participation for heritage conservation. En VERDELLI, L. (ed.) Sustainability in Heritage Protected Areas. Wroclaw: AESOP, 2015, pp. 88-95

- DAWSON, T.; VERMEHREN, A.; MILLER, A. et ál. (2013) Digitally Enhanced Community Rescue Archaeology. En 2013 Digital Heritage International Congress (DigitalHeritage). sl: IEEE, 2013, vol. 2, pp. 29-36

- JIMÉNEZ-ESQUINAS, G.; SÁNCHEZ-CARRETERO, C. (2015) Mediaciones patrimoniales para relaciones incendiarias: el caso del santuario da Virxe da Barca de Muxía. revista $\mathrm{PH}$, n. ${ }^{\circ} 88$, pp. 2-8

- PARENTE, M. (2012) Affermare l'identita dei territori. Ottagono, XLVII

- RAUTENBERG, M. (1998) L'émergence patrimoniale de l'ethnologie entre mémoire et politiques publiques. En POULOT, D. (ed.) Patrimoine et modernite. Paris: L'Harmatan , pp.279-291

- TWEED, C.; SUTHERLAND, M. (2007) Built cultural heritage and sustainable urban development. Landscape and Urban Planning, n. ${ }^{\circ} 83: 1$, pp. $62-9$ <http://dx.doi.org/10.1016/j. landurbplan.2007.05.008> [Consulta: 30/08/2016] 